\title{
A difícil vida da encenação em Portugal
}

\section{Rui Pina Coelho}

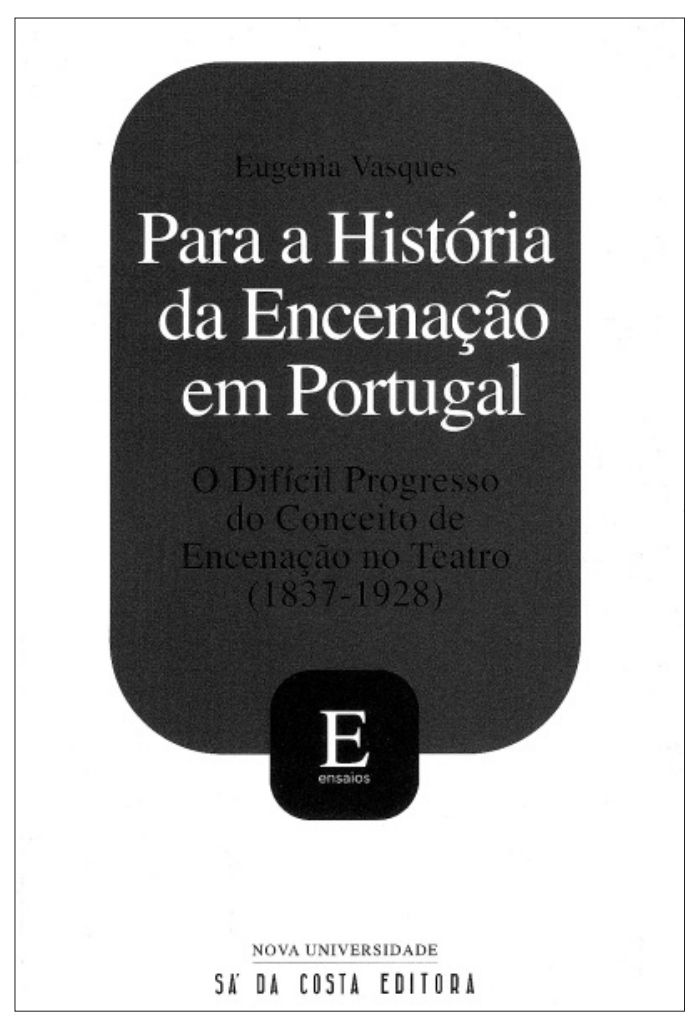

Num momento em que se proclama com entusiasmo o fim da encenação e se declara a morte do encenador, não deixa de ser significativo que se apresente aqui uma obra que visa, precisamente, fazer a cartografia da evolução dificil, como a autora avisa logo no subtítulo - do conceito de encenação no teatro, em Portugal, de meados da segunda metade do século XIX ao ano de 1928. 0 objectivo não é, evidentemente, passar o óbito final a esta profissão mas sim confirmar que "para entendermos as actuais vicissitudes do teatro em Portugal e, em particular, as vicissitudes do ser encenador/encenadora no nosso teatro (lato sensu), ainda hoje, necessário será percorrer, com o auxílio de textos antigos de reflexão, alguns dos caminhos trilhados pelos nossos maiores, desvendando ou pelo menos tentando interpretar como se foi 'instalando' entre nós, por imitação ou por recriação, a difícil e exigente 'arte de representar'" (p. 7).

A baliza temporal prende-se, não com mudanças sócio-políticas, mas com razões endógenas ao próprio fazer teatral - embora a margem final coincida aproximadamente com o definitivo esgotar do fulgor republicano, que também se traduzia em arrojadas experimentações cénicas no início do século $X X$, e que com o Estado Novo (1926-1974) vai ser sacrificado em
Eugénia Vasques, Para a história da encenação em Portugal: $O$ difícil progresso do conceito de encenação no teatro (1837-1928), Lisboa, Sá da Costa Editora, Colecção Nova Universidade, 2010, $160 \mathrm{pp}$.

nome de um teatro tristemente domado e genericamente comercial. Assim, a cronologia compreendida nesta obra de Eugénia Vasques - professora, crítica, investigadora de reputados créditos - prende-se com as datas de publicação dos textos onde o estudo colhe os seus argumentos: 0 terceiro número de 0 Entre-acto: Jornal dos teatros (1837), Poeira do teatro, de Carlos Santos (1928) e A religião do teatro, de Eduardo Scarlatti (1928). Entre estas duas datas e quando se trata da encenação, são chamadas à colação textos de Teixeira Bastos ("0 teatro moderno em Portugal"), Simões Coelho (Paradoxo da enscenação: Teoria e prática), Afonso Gaio (Evolução do teatro português contemporâneo), Augusto Garraio (Manual do artista dramático), Augusto de Lacerda (Manual do curioso dramático), Manuel de Macedo (A arte no teatro e Arte dramática), Victor Machado (Guia prático de encenação), Augusto de Melo (Manual do ensaiador dramático), Henrique Lopes de Mendonça (A crise do teatro português), J. A. Moniz (com Simões Coelho, Arte de representar: Caracteres e Arte de representar: Sentimento, expressão, identificação), Eduardo Noronha (Reminiscência do tablado), Guedes de Oliveira (Jornal dum espectador), Joaquim de Oliveira (O Teatro Novo), Colares Pereira e Joaquim Miranda (Revista Teatra), António Pinheiro (Teatro português: Arte e artistas), Júlio Lourenço Pinto (Estética Naturalista: Estudos criticos), Augusto Ricardo (Memórias e estudos), Augusto Rosa (Memórias e estudos) e Sousa Bastos (Coisas de teatro), entre outros ${ }^{1}$. São textos de diferentes matizes: ensaios, artigos, críticas, tratados, memórias, reflexões críticas, projectos, uns mais normativos, outros mais descritivos, assinados por autores de variadissimas proveniências: "amadores esclarecidos e directamente interessados (...), por actores-ensaiadores ou dramaturgos e empresários, também docentes (...) ou críticos dramáticos em jornais e revistas de referência" (10-11). Em todos, ora directamente, ora indirectamente, se aborda a encenação, as suas virtudes, as suas falências, a sua natureza, os seus modos de fazer ou as suas possibilidades técnicas. Vasques vai colhendo neles o que se diz e descobrindo o que se entende por encenação, numa perspectiva diacrónica, oferecendo ao leitor um mapa sobre a evolução deste conceito entre os fazedores nacionais. Mapa tão mais importante se recordarmos que António Pedro, encenador do pós-Segunda Guerra Mundial é normalmente citado como o primeiro "encenador"
1 Para informações bibliográficas detalhadas, conferir a bibliografia da obra em análise (pp.85-89). 
português (ainda que este - tal como Rogério Paulo sinalizasse, e muito justamente, Araújo Pereira, protagonista de várias tentativas experimentais do início do século $X X_{1}$ como o verdadeiro "primeiro encenador").

0 estudo de Eugénia Vasques distribui-se numa entrada, quatro capítulos e uma saída. Na "Entrada" tratase "Da impossibilidade do naturalismo em Portugal e das suas consequências", arrumada em sete pontos. Aí, revelamse logo alguns dos denominadores comuns da obra: rebatem-se os preconceitos contra a figura do encenador grafam-se os nomes dos autores e dos grupos que primeiro "apontam" e discutem a noção de encenação em Portugal, aponta-se a atávica atracção por Paris e pela cultura francófona e sinalizam-se as influências do teatro transpirenaico, para em seguida se atentar "como o termo 'encenação' foi penetrando no léxico do nosso teatro amador e profissional entre meados do século XIX e meados dos anos vinte do século seguinte" (15).

No capitulo 1 ("Da naturalidade ao naturalismo: entrada do ensaiador (1837-1923)" seguem-se atentamente os tímidos indícios que vão dando conta da autonomização do ensaiador e do aparecimento da noção de "enscenação", para no segundo capítulo dar se acompanhar a "Evolução do conceito de Mise-en-scène no léxico teatral português (1890-1895)". Aí, apresenta-se a seminal obra de Becq de Fouquières, L'art de la Mise-en-scène: Essai d'esthétique théâtrale (1884), "uma obra de reflexão filosófica sobre as relações 'perigosas' entre a encenação e a obra dramática que constitui uma chamada de atenção para 'os excessos' suscitados pela escola realista-naturalista" (p.33), e escutam-se os seus ecos na teorização portuguesa sua contemporânea, no Manual do ensaiador dramático, de Augusto de Melo (1890), um "importante manual de explicação da arte do ensaiador"' (p. 43); no Manual do Artista Dramático, de Augusto Garraio (1892), "um guia prático de divulgação destinado aos amadores, ou curiosos dramáticos, que não possam dispor de um ensaiador profissional para a elaboração das suas récitas (p. 46); e no artigo "Estudos e doutrinas: Da Mise en-scène", de Augusto de Lacerda (1895), publicado em duas partes na Revista teatral, "onde se faz a apologia dos novos processos teatrais inspirados no naturalismo" (p. 49). No terceiro capitulo, trata-se da frágil "Afirmação do encenador (1890-1928)", atestada na bibliografia consultada e sinalizando a desadequação da cena nacional para o estabelecimento sólido da encenação, contrariamente ao que ia acontecendo na restante Europa teatral. 0 último capítulo, "Terrenos de luta: 0 'teatro-religião', a encenação e o cinema (1910-1927) explora a procura da especificidade da linguagem do teatro face ao emergente cinema, e a importância que a figura do encenador enquanto portador de uma visão artística individual a organizar todos os elementos do espectáculo terá, centrando-se na exposição dos iluminados argumentos de Eduardo Scarlatti, em Ideias de outros e A religião do teatro (estranha-se, contudo, a ausência de uma obra de 1924, de Augusto Lacerda, Teatro Futuro: Visão de uma nova dramaturgia, onde se afirma, a título de exemplo: "para vencer a perigosa concorrente, o Teatro precisa de impor o secular prestígio, remodelando os desacreditados processos. Teoricamente nada mais fácil; praticamente, nada mais simples, dêsque [sic] os esforços intelectuais e materiais se congreguem fortemente. A cinematografia não satisfaz ao conjunto de requisitos que Ihe dariam legitimamente a classificação de pura arte. Está para o teatro como a vulgar fotografia está para a pintura (p. 115)".

A "Saída" ("A construção titubeante de uma definição de encenação"), mais do que encerrar a discussão ou fazer um balanço, avança para novas coordenadas, mais concretamente, para o pós-Segunda Guerra Mundial altura em que se ensaia em Portugal um efémero movimento de teatro experimental e onde a figura do encenador se vai finalmente firmando. Assim, divide-se a conclusão em dois momentos: de 1884 a 1912, e de 1921 a 1949, esticando o corpus em análise até aos Cinquenta anos de teatro, de Carlos Santos e de A propósito do teatro, de José Gamboa, de 1949. Os parágrafos finais, que explicam "Porque não vingou o naturalismo" em Portugal, acrescentam que "são razões políticas, geradoras da profunda iliteracia e atraso no meio teatral e no ensino do Conservatório, que estão na base da impossibilidade de uma implantação do naturalismo numa cena que conheceu pouca intervenção de artistas exógenos ao teatro" (83). E, grosso modo, será esta a realidade até que 1974 e a revolução de Abril resgate o fazer teatral em Portugal da sua exiguidade.

Com esta obra, Eugénia Vasques resgata igualmente de um confortável silêncio alguns dos mais centrais artistas ou intervenientes na vida cultural portuguesa do fim do século XIX e início do século XX, reunindo uma colecção invejável de textos que se encontram fora de circulação comercial ou em mais restrito acesso e em acervos especializados. Além disso, a riquíssima antologia de textos (pp. 93 a 157), as extensas citações, as constantes chamadas de atenção a negrito, destacando as ideias principais, e as profusas exclamações, denotam o carácter eminentemente didáctico da obra, dirigida, antes de mais nada, a alunos e estudiosos de teatro, sendo este estudo uma informada antologia comentada e anotada, poupando na complexificação excessiva dos temas em benefício da clareza e sistematização. Esta obra servirá de base a muitos outros estudos, que encontrarão aqui, seguramente, material fértil (e reunido) para encetar novas aventuras (tão necessárias) pela história do teatro em Portugal. 